\title{
Arduino Based Color Sorting Machine using TCS3200 Color Sensor
}

\author{
Ch.Shravani, G. Indira, V. Appalaraju
}

\begin{abstract}
Sorting of object is an essential mechanical process in which difficult work is quite required. Chronic manual arranging makes consistency troubles. Machines can perform mainly dreary assignments superior to human beings. Laborer exhaustion on sequential manufacturing structures can result in decreased execution, and purpose troubles in retaining up object fine. A employee who has been appearing research undertaking over and over may additionally in the end forget about to recognize the color of item, but a machine in no way. On this paper a compact records close to arranging of articles based totally totally on shading has been implemented making use of TCS3200 shading sensor with SERVOMOTORS associated with AURDINO UNO.
\end{abstract}

Index Terms-Color sorting, Conveyor belt, TCS3200 color sensor, ARDUINO UNO, Servomotors

\section{INTRODUCTION}

In the cutting-edge-day scenario of competitive manufacturing in commercial zone performance of manufacturing holds the important component for achievement. It's miles essential to beautify manufacturing pace, lower the labour charge and reduce the breakdown time of production gadget.

Merchandise should be taken care of in numerous ranges of manufacturing and manual sorting is time consuming and labour extensive. This paper discusses about the automatic sorting tool which helps the sorting mechanism to kind based at the coloration. For sensing TCS3200 coloration sensor has been used. With the aid of reading the frequency of the output of the sensor, color primarily based absolutely sorting is completed.

Layout of a innovative venture referred to as item sorting system by means of spotting the only of a kind shades of the item has been leader goal of the challenge. Accumulating the objects from the hopper and distributes those objects to their accurate area based on their coloration even they'll be unique in coloration. Many paintings environments aren't suitable for manual sorting and a few areas are risky for humans to paintings on. Consequently to avoid the unstable work, time consumption and hard paintings catch 22 situation. This prototype is built as a simple digital gadgets like microcontroller for processing, Servo motors for actions and coloration sensor for recognizing exclusive colored devices.

Revised Manuscript Received on April 12, 2019.

Ch.Shravani, Electronics and Communication Engineering, Vignan's Institute of Information Technology, Visakhapatnam, A.P, India. (E-mail: shravanichandaka11@gmail.com)

G. Indira, Electronics and Communication Engineering, Vignan's Institute of Information Technology, Visakhapatnam, A.P, India. (E-mail: gedela.indira@gmail.com)

V. Appalaraju, Electronics and Communication Engineering, Vignan's Institute of Information Technology, Visakhapatnam, A.P, India. (E-mail: appalrajuvadaboyina@gmail)

\section{APPROACH}

This venture makes use of a simplified and not steeplypriced technique for sorting the substances of a unique colored items, it's far sensing the color of the object and kind out the different colored devices. Servo automobiles are used to manipulate the motion of the skittles are amassed on the hopper. A servo motor is used to pressure the skittles to the sensor and the sensor that is interfaced with ARDUINO identifies the shade of the object and the bottom servo is operated as consistent with the deliver code.

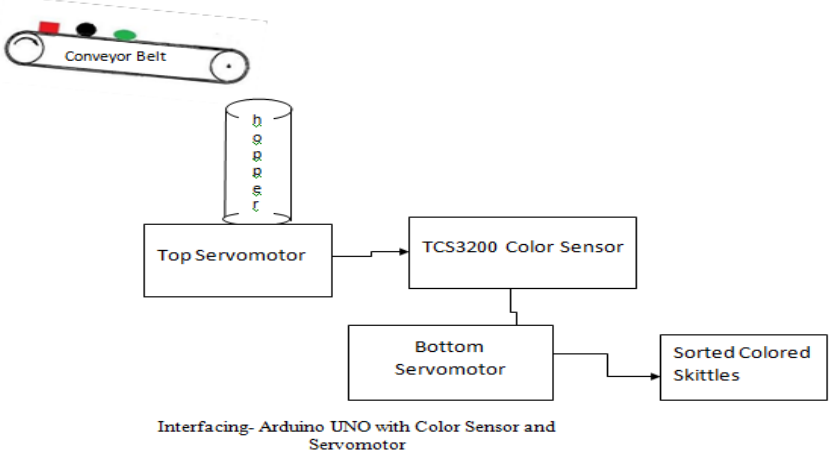

Figure 1: Block Diagram of the System

\section{A. Input Unit}

The precept goal of the work is to move the object from specific spot to sensor unit. On the factor at the same time as the object is introduced to the sensor a directing rail is made to prevent. Proper here field is the important statistics unit. Field is going to accumulate all the shaded items and drives personally toward the sensor unit with the help of pinnacle servo engine. We are able to make use of any of the shaded gadgets in step with the mechanical factors of the device. The essential hued objects we are going to use right here are colored skittles like gem stones, Marbles and so forth. The essential employment of this unit is to transport the object shape a gap to sensor unit, while the object goes to the sensor unit the manual rail desires to prevent.

\section{B. Processing Unit}

This unit gives pointers at the same time as the item emerges at the directing rail. With the help of servomotor and makes a decision the coloration of the item with the assist of the TCS3200 shading sensor and sends those sign to the control unit for subsequent operational advances.

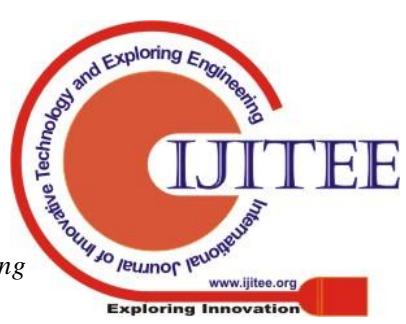


Right right here the coping with is virtually relies upon in the deferral gave to the top servo engine. Thru giving a splendid degree of postpone lets in in best acknowledgment of $R, G, B$ pressure estimations of each deal with. The making prepared is likewise based totally on the interfacing of shading sensor with Arduino UNO. Right right here we're able to supplant Arduino UNO with Arduino Nano.

\section{Output Unit}

The unit is directed with the aid of the manipulate unit for the deciding on and putting of the item from the shipping unit to explicit spot contingent upon the colour of the object. Every shading is accumulated at numerous devices.

As an instance, any shading from red, green or blue is stored for discovery in advance than the shading sensor then an appropriate shading drove is grew to emerge as on and the yield of the detecting of shading is visible. Inside the first place, we keep the inexperienced shading paper over the shading sensor, it acknowledges and turns the drove on and further, approach is performed for the alternative two colorings.

\section{RESULTS}

According to the shading primarily based the gadgets are selected and hauled to the predetermined field. Those which can be to be isolated can be reinforced into the box. A shading sensor detects the subjects coming in its sight and code for the equal is coded in Arduino in order that solitary the quality article colorings are detected and accumulated within the times toward the give up making use of servo engines.

On the issue at the same time as any shading from red, inexperienced or blue is saved for location earlier than the shading sensor then the correct shading drove is have become on and the yield of the detecting of shading is seen. Initially, we hold completed for the opportunity shading which location is seemed in $\mathrm{p}$ the inexperienced shading paper over the shading sensor, it acknowledges and turns the drove on and in addition, method is completed for the opportunity shades.

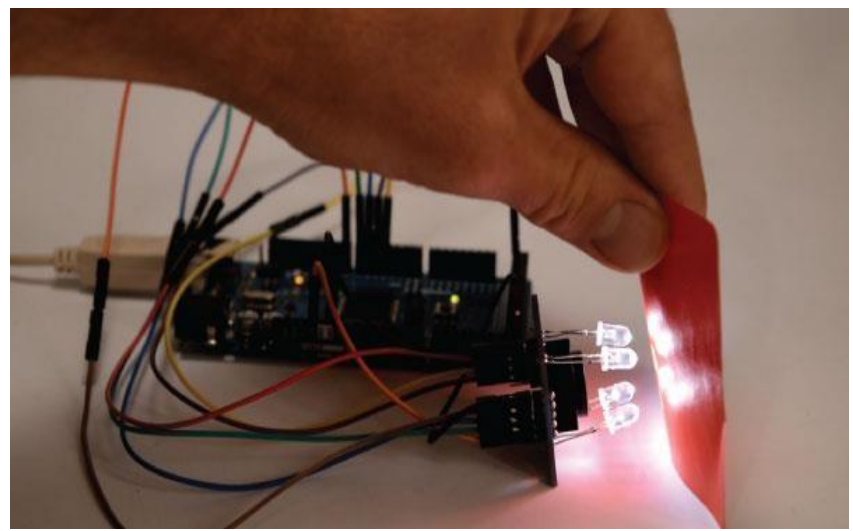

Figure 2: Diagram Showing the Color Detection

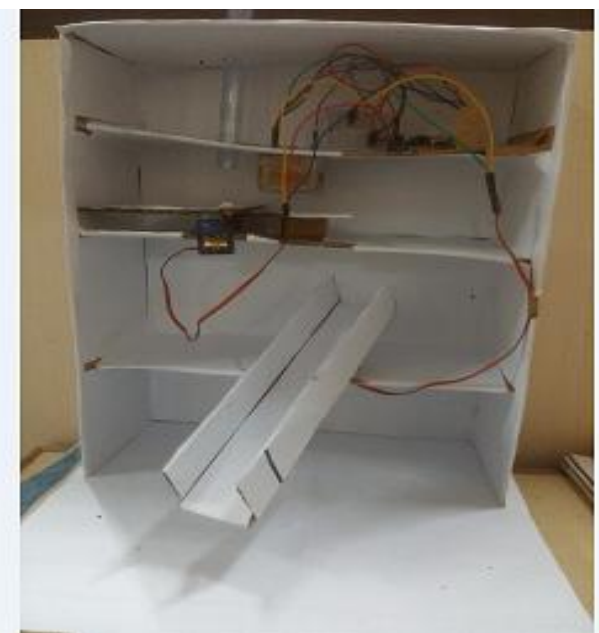

Figure 3: Color Sorter model
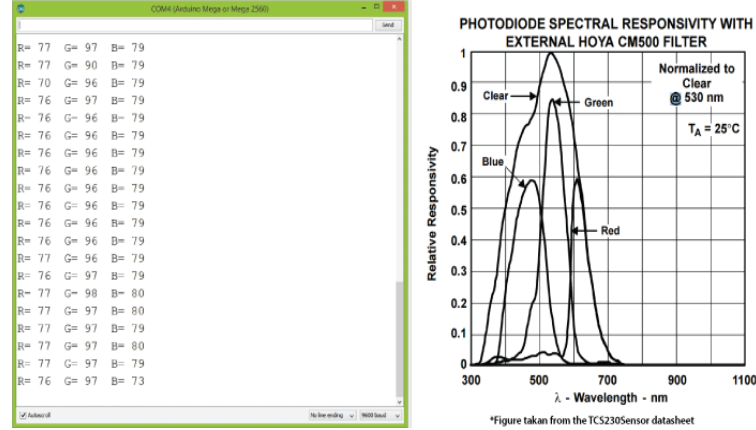

Figure 4: Serial Monitor Output

At the off hazard that we run the Serial monitor we are able to begin getting some qualities. These traits rely on the selected recurrence scaling, simply as from the encompassing lights. Be aware right here that 3 trends evaluation because of the severa affectability of each photodiode type, as determined from the photodiode phantom responsively define from the datasheet of the sensor. With the aid of the by way of manner of, currently how approximately we recognize how the features reply even as we will get numerous colours front of the sensor. So as an example, on the off danger that we supply crimson shading, the underlying well worth will drop down, for my situation from spherical 70 to round 25.

So now on the off hazard that we need to speak to the diagnosed colorations with the RGB version which has values from 0 to 255 , we are able to make use of the manual () potential to manual or exchange over the readings to the trends from 0 to 255 . The estimation of 70 may be mapped to zero, and the estimation of 25 to 255 . A comparable system goes for the two one-of-a-kind colorings.

\section{CONCLUSION}

On the component even as any object of hues, as an instance, crimson, green, Blue is stored near the sensor, the shading LED of the comparing kind is grew to grow to be on giving the yield of the sensor. Inexperienced shading is tried on the begin and pursued through different 
On the factor even as the sequential display is all commenced, a few developments appeared with the aid of manner of the start recurrence scaling relying upon the environment. It is probably noticed that the capabilities are numerous due to numerous sensor photodiodes, contingent upon the ghastly response on hand inside the sensor. In this paintings noticing those estimations of reaction is very tremendous. As an example of purple shading is delivered, the underlying clearly worth is going much less even from 70 to twenty-five.

For portrayal inside the RGB model which has values for 0 to 255 , the guide (), capability is applied to delineate assent esteems from 0 to 255. Similar pre coding can be linked for each single one-of-a-kind shading. The version is intended for arranging any item of any form which having length beneath $2 \mathrm{~cm}$. The version is meant to type diverse tablets of RGB colorings and at time it has the capacity to get up to one hundred pills and type with a hundred\% precision. The DC servomotor is prepared to pivot for various plots for each shading isolated. This version can be stretched out to ongoing programs in pharmaceutical ventures and bundling corporations. It moreover can likewise be robotized. Rapid engines deliver full-size outcomes for mechanical applications.

\section{REFERENCES}

1. C. Zhang and adequate. S. Suslick, "Colorimetric sensor cluster for soda pop research", J. Agric food Chem, vol fifty 5, pp 237-242, 2007.

2. P. D. Oram and J. Strine, "Shading estimation of a strong dynamic pharmaceutical fixing as a guide to spotting key gadget Parameters", J. Pharm Biomed Anal, vol forty, pp 1021-1024, 2006.

3. M. Candid, Nobert Kaiser, Wolfgang Buss, Ramona Eberhardt, "speedy mechanical shading and characteristic sensors, digital Imaging", pp 50-fifty seven, 1999.

4. A. Pacquit, J. Frisby, Danny Diamond, King Tong Lau, Alan Farrell, Brid Quilty, Dermot Diamond, "improvement of a smart bundling for the checking of fish waste", meals Chem, vol 102, pp 466-470, 2007.

5. E. J. Cadieux Jr, "Framework and strategy for outwardly analyzing a cigarette bundling gadget", ed: Google Patents, 2002.

6. D.J. Lee and R. S. Anbalagan, "fast robotized colorsorting imaginative and prescient device $\square$, in Optical Engineering Midwest", pp 573-579, 1995.

7. J. V. Popov-Ralji, et al, "Examinations of bread introduction with deferred staling applying instrumental estimations of bread scrap shading", Sensors, vol nine, pp 8613-8623, 2009.

8. J. V. Popov-Ralji and J. G. Lalii-Petronijevi, "Tangible houses and shading estimations of dietary candies with numerous corporations at some point of ability for so long as 360 days", Sensors, vol nine, pp 1996-2016, 2009.

9. R. Bogue, "Optical compound sensors for cutting-edge applications", Sensor overview, vol 27, pp 86-ninety, 2007.

10. R. Baribeau, "Shading reflectance displaying making use of a polychromatic laser expand sensor", IEEE T pattern. Buttcentric., vol. 14, pp. 263-269, 1992.

11. H. Escid, et al., "zero. $35 \mathrm{~mm}$ CMOS optical sensor for an integrated transimpedance circuit", the global mag on clever Sensing and clever systems, vol. four, no. three, pp. 467481, September 2011.

12. Norfazlinda Binti Daud, "Use of colours sensor in a automatic framework", Technical college Malaysia, may 2007.

13. Bickman, Josh, "Mechanized coloration-Sorting makes use of optical innovation", vol. thirteen, 1996.
14. Bozma and Yal-cin, "visible managing and grouping of things on a transferring delivery: a specific discernment method", vol. 18, problem 2, 2002.

15. C Boukouvalas, J Kittler, R Marik, M Mirmehdi and Petrou, "Earthenware tile research for shading and easy defects", university of Surrey, 1995.

16. R Mattone, G. Campagiorni, F. Galati, "Arranging of factors on a moving transport line. Part1: a method for recognizing and arranging gadgets", vol. sixteen, troubles 2-three, 1999.

\section{AUTHORS PROFILE}

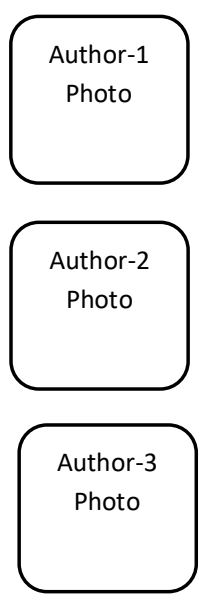

Ch.Shravani, M.tech (Ph.D), areas of interest are Image processing, GPGS architectures and Evolvable Hardare.

G.Indira, M.tech , Areas of interest are Analog circuits, Signal processing and VLSI.

V.Appalaraju , M.Tech, areas of interest are RADAR signal processing, Antennas. 